\title{
Theoretical Analysis of the Impact of Technological Innovation and Social Responsibility on Financial Performance
}

\author{
Cui Guo \\ School of Accountancy, Shandong Women's University, Jinan, Shandong, China
}

\begin{abstract}
In today's society, innovation and sustainable development are more and more widely concerned. Technological innovation and social responsibility have become an important part of enterprise strategic decision-making activities. The role, theoretical basis and implementation effect of enterprises in technological innovation and social responsibility have also become the focus of academic attention. This paper introduces the theories related to technological innovation and social responsibility fulfillment, expounds the mechanism of their impact on financial performance, and puts forward some effective countermeasures for enterprises on the premise of establishing a theoretical basis.
\end{abstract}

Keywords: Technological innovation, Social responsibility, Financial performance.

\section{Introduction}

With the adjustment of enterprise registration conditions, the number of enterprises is more and more, the competition among enterprises is more and more fierce, and the internal and external environment of operation is becoming more and more complex. For enterprises, profit is the premise to carry out various activities. Enterprises will not be able to do anything without the support of funds, so many enterprises actively take measures to improve their financial performance. Under the strategy of innovation-driven development, making use of Internet technology to innovate and develop enterprises has become a top priority. Using the Internet to carry out technological innovation will lead enterprises to take a leading position in the industry, change the mode of operation, have a prominent competitive advantage, have a good production and sales situation, and naturally significantly improve their financial performance. In addition, success comes from harmony and strength comes from unity. There are many subjects related to the enterprises, and the enterprises must live in harmony with these related subjects and ensure long-term cooperative relationship, so as to ensure the steady improvement of financial performance. According to the company law, enterprises must abide by the laws and regulations, operate in good faith, abide by social morality, voluntarily accept social supervision, and actively fulfill their social responsibilities. With the determination of enterprises to be self-reliant and innovate independently combined with the joint efforts of enterprises and other stakeholders, the financial performance of enterprises will be greatly improved.

\section{Analysis of the Impact of Technological Innovation on Financial Performance}

With the rise of Internet technology, all walks of life have come up with innovative approaches. The development of enterprises can not be separated from technological innovation, and the competitive advantage among enterprises also depends on technological innovation. Enterprises carry out technological innovation activities by hiring research and development teams with high salaries, developing new products, introducing advanced production lines and other means, and finally achieve high profits and strong competitive advantages, and achieve a great improvement in financial performance.

The theory of technological innovation at the enterprise level holds that the enterprise must consider the technological innovation activities in all aspects, and all aspects of the enterprise need to add innovation elements. In financing activities, enterprises should innovate the financing methods and introduce investors reasonably in the principle of low cost. In investment activities, enterprises should optimize the allocation of funds and invest funds into the frontier of innovation based on the principle of high income and low risk. In the operation activities, enterprises should create new production conditions and production factors, form new technologies, innovate and perfect the management of supply chain. In line with the principle of reducing operating cost, improving product quality, reducing waste rate and increasing market share, the enterprise will improve operation efficiency, create more operating results, and finally create competitive advantage. In the profit distribution activities, enterprises should introduce innovative distribution mechanism to drive the enthusiasm and satisfaction of investors, and finally get the result of investment expansion. Through the optimal combination of financing, investment, operation and profit distribution four types of financial management activities, the financial performance of the enterprise will be greatly improved. In addition, with the change of business environment, enterprises constantly innovate the organizational form, break through the rigid thinking limitation in the construction of enterprise culture, introduce innovation mechanism and establish new management mode. These practices will also play a certain auxiliary role in improving financial performance.

According to the resource-based theory of enterprises, there are many resources in an enterprise, including tangible and intangible resources, such as monetary capital, fixed assets, 
patented technology, and human resources and so on. These resources can bring value and competitive advantage to the enterprise, which are different from the resources of other enterprises and cannot be completely copied by other enterprises. The enterprise will form a unique strategic management ability by rational allocation, optimization and integration of these resources. At the same time, the unique advantages generated by these heterogeneous resources are also sustainable and long-term, and play a significant role in improving the financial performance of enterprises. Therefore, as a unique resource of enterprises, technological innovation can bring lasting competitive advantages to enterprises, and achieve a good situation of low cost, high profit and fast turnover, which is one of the indispensable factors to improve the financial performance of enterprises.

In view of the technological innovation theory and resource-based theory at the enterprise level, it is beneficial for enterprises to carry out all kinds of activities by technological innovation. Moreover, technological innovation is aimed at the integration and optimization of the existing resources of enterprises, which will eventually make enterprises have basic advantages in terms of resources. The purpose of enterprises is to make profits. Technological innovation improves the financial performance of enterprises with the help of special resource advantages.

\section{Analysis of the Impact of Social Responsibility on Financial Performance}

With the improvement of various internal systems and the requirements of social stability, the view of social responsibility is accepted by more and more enterprises. The premise of gradual development and sustainable profit of enterprises is not only to assume economic and legal responsibilities, but also to be responsible for the environment and the public, that is, to assume social responsibilities. The proposal of corporate social responsibility is conducive to the establishment of a good image of the enterprise, the strong support from all aspects, and the realization of sustainable development.

According to stakeholder theory, running a business need to establish a fair contractual relationship with many stakeholders, including the government, consumers, suppliers, creditors, employees, communities and other subjects. Enterprises must consider the interests of all stakeholders when they formulate enterprise systems and plan their future development. For example, enterprises must consider the physical and mental health and safety of employees, and pay attention to their life demands; Enterprises must consider their financial strategy to ensure that the balance of funds at the end of the period can pay interest, tax, etc., and meet the legitimate rights and interests of creditors and tax departments; Enterprises must abide by the credit, reasonably arrange funds, pay the goods within the agreed time, and maintain good long-term cooperative relations with suppliers; Enterprises must consider the quality of products or services, pay attention to product replacement and follow-up maintenance services, and meet the needs of consumers; Enterprises must take into account the environmental pollution caused by industrial waste gas and waste water, as well as the disturbance caused by noise to the residents of the nearby communities, and fulfill their obligations to protect the environment; Enterprises should give full consideration to public welfare and charity activities, respond to the public welfare policies put forward by the state, and help the poverty alleviation strategy. If the interests of any kind of subject are not satisfied, the image of the enterprise will also be affected, which will eventually restrict the development and growth of the enterprise. In view of the theory of stakeholders, the state, relevant institutions and enterprises have begun to pay attention to the implementation of corporate social responsibility, and strive for improvement in corporate performance. The State advocates that enterprises adjust the previous idea of "shareholder first" to the new idea of "customer-employee-shareholder" interests satisfaction order. Nowadays, the criterion of evaluating the success of enterprise management is not only profit, but also whether it satisfies the interests of various subjects while realizing profit. Every link of enterprise operation has the requirement of fulfilling social responsibility, and the procurement, production, sales and other links will involve different interest stakeholders. Therefore, it is necessary for enterprises to fulfill social responsibility for different interest subjects in each link. Many institutions, such as The China Insurance Regulatory Commission and China Banking Regulatory Commission, have put forward different requirements for social responsibility according to the nature of enterprises within their jurisdiction. In 2008, the State-owned Assets Supervision and Administration Commission of the State Council put forward the principles and specific guidance requirements for the state-owned enterprises to fulfill their social responsibilities. In order to encourage enterprises to fulfill their social responsibilities, Shanghai Stock Exchange put forward the value of social contribution per share for the first time, and called on enterprises to issue social responsibility reports, which should be reviewed by a third party if necessary. Enterprises actively meet the requirements of the state and relevant institutions for social responsibility, pay attention to quality, innovation, reputation, culture and other factors, improve the cognition of social responsibility, expand the coverage of social responsibility, and innovate the means to implement social responsibility.

The advocacy of the state and relevant institutions, as well as the self-consciousness of enterprises, make the overall situation of social responsibility performance tend to be good, which will inevitably lead to the improvement of the relationship between enterprises and multi-stakeholders. Enterprises actively fulfill their social responsibilities to maintain their corporate image, improve their reputation, attract consumers and suppliers to maintain long-term cooperative relations with them, and get strong support from the government in terms of taxes, financial subsidies and other aspects as well as financial institutions in terms of loans. At the same time, there will be more investors willing to invest cash, fixed assets, patented technology and so on to help enterprises grow further. With the support of many stakeholders, the enterprise will usher in a good situation of 
increasing sales revenue, fast asset turnover and improved profit, which will eventually improve the financial performance to a greater extent.

To sum up, based on the stakeholder theory, enterprises try their best to fulfill their social responsibilities to all stakeholders, which will eventually return the feedback of all stakeholders, get better financial performance, and achieve a win-win situation between enterprises and stakeholders.

\section{Suggestions}

The above theoretical analysis provides an effective reference for enterprises to improve their financial performance. Enterprises should attach great importance to technological innovation and the fulfillment of social responsibility. First, they should affirm the importance of both ideologically, and then take measures in action.

\subsection{Carry out Technological Innovation Activities and Make Full Use of the Advantages of Heterogeneous Resources}

Enterprises can not ignore innovation all the time. They can carry out technological innovation according to the requirements of ecological environment in social responsibility, and formulate the overall technological innovation strategy of the enterprise. On the one hand, they can form a research and development team to grasp the cutting-edge information and technology in the field at any time. On the other hand, they can grasp the requirements of the new era, move according to the time and the situation and fully consider innovative factors in product design, product type and product production process. At the same time, enterprises can use the advantage of heterogeneous resources to innovate, improve the efficiency of resource use and maximize the value.

\subsection{Fulfill Corporate Social Responsibility and Actively Pay Attention to the Interests of Stakeholders}

On the one hand, enterprises must strengthen the awareness of social responsibility performance, take the initiative and voluntarily disclose corporate social responsibility information and accept social supervision. In addition, enterprises also need to transfer the implementation of social responsibility from the consciousness level to the practical action, so as to ensure the effective implementation of policies and plans.

On the other hand, the fulfillment of corporate social responsibility can not be separated from the government, which is "visible hand". As the visible hand of economic activities, the government should give full play to its role, encourage enterprises to fulfill their social responsibilities and play a good role as a guider. First of all, it should be regulated from the perspective of law and clarify the relevant laws to be followed in the fulfillment of corporate social responsibility; Secondly, enterprises should establish social responsibility evaluation system and disclosure standards based on the characteristics of the industry, so as to provide incentive measures and policy support for enterprises with good performance of social responsibility.

Under the guidance of technological innovation theory, resource-based theory and stakeholder theory, enterprises deeply understand the influence mechanism, carry out technological innovation activities to the maximum potential, fulfill corporate social responsibility, and ultimately achieve the effective improvement of financial performance.

\section{Acknowledgement}

This research was financially supported by Youth research project of Shangdong Women's University issues "Research on the relationship between corporate innovation investment, social responsibility and financial performance (Grant No. 2017YB04)".

\section{References}

[1] Yanxiaoxia. The study on the impact of environmental responsibility and technological innovation on financial performance of heavily polluted enterprises [D]. Xi'an Engineering University, 2019

[2] Wang Zhengjun, Xie Xiao. Corporate social responsibility performance, $\mathrm{R} \& \mathrm{D}$ investment and financial performance--Based on the perspective of internal and external stakeholders $[\mathrm{J}]$. Communication of Finance and Accounting, 2020 (07): 51-55 